\title{
ERRATUM
}

Sunggil Kim $\cdot$ Kil-Sun Yoo $\cdot$ Leonard M. Pike

\section{Development of a co-dominant, PCR-based marker for allelic selection of the pink trait in onions (Allium cepa), based on the insertion mutation in the promoter of the anthocyanidin synthase gene}

\section{Theor Appl Genet (2005) 110:628-633}

Owing to technical problems, this article appeared in both Volume 110 Number 3 (pp 573-578) and in
Volume 110 Number 4 (pp 628-633). Please note that the former is the correct version. We apologize for this unfortunate error and for any inconvenience caused.

The online version of the original article can be found at http:// dx.doi.org/10.1007/s00122-004-1884-5

S. Kim $\cdot$ K.-S. Yoo $\cdot$ L. M. Pike $(\bowtie)$

Vegetable and Fruit Improvement Center,

Department of Horticultural Sciences,

Texas A\&M University, College Station,

TX 77843, USA

E-mail: 1-pike@tamu.edu

Fax: + 1-979-8424522 